\title{
Polidez no Brasil e na Espanha: um estudo de caso comparativo
}

\author{
Enrique HUELVA UNTERBÄUMEN ${ }^{1}$ \\ Universidade de Brasilia - UnB \\ buelva@unb.br \\ Helena SANTIAGO VIGATA2 \\ Universidade de Brasilia - UnB \\ subtitulando@gmail.com
}

\section{Yamilka RABASA FERNÁNDEZ ${ }^{3}$ \\ Universidade de Brasilia - UnB \\ yamilkafer@gmail.com}

"A franqueza, sem as regras da polidez, é grosseria".

Confúcio

\section{Resumo}

Este trabalho tem por objetivo desenvolver um estudo comparativo entre as estratégias de polidez que seriam utilizadas em português e em espanhol por quatro professoras universitárias de espanhol, duas espanholas e duas brasileiras, em doze situações hipotéticas apresentadas a elas mediante questionários de hábitos sociais. A pesquisa espelhou-se em um estudo realizado por Piatti (2003) na Argentina, onde a autora observou as diferenças pragmáticas existentes entre um grupo de estudantes estrangeiros de espanhol e um grupo de falantes nativos argentinos. Com um perfil diferente de participantes, quatro professoras que transitam facilmente entre as duas línguas e culturas, buscou-se ampliar as reflexões sobre a

Doutor em Linguística e professor do Departamento de Línguas Estrangeiras e Tradução da UnB.

Mestre em Linguística Aplicada e professora do Departamento de Línguas Estrangeiras e Tradução da UnB.

3 Mestranda em Linguística Aplicada pelo Departamento de Línguas Estrangeiras e Tradução da UnB. 
competência pragmática e sobre as diferenças interculturais entre brasileiros e espanhóis. A partir dos resultados obtidos, tentamos estabelecer algumas diferenças interculturais entre as estratégias de polidez utilizadas no Brasil e na Espanha.

Palavras-chave: estratégias de polidez; questionários de hábitos sociais; diferenças interculturais Brasil-Espanha.

\section{Abstract}

The aim of this paper is to present some results of a comparative study between the politeness strategies that two Spanish and two Brazilian professors would use, both in Portuguese and Spanish, in twelve hypothetical situations presented on a social behavior questionnaire. This work is based on a previous study published by Piatti (2003) in Argentina, where the author observed some pragmatic differences between a group of students of Spanish as a foreign language and a group of native speakers of the language. With her hypotheses as a starting point, the scope was moved to a small group of people with high communicative competence in both languages, in order to give a different insight on of the pragmatic differences that exist between Brazilians and the Spanish. Based on the findings, we have tried to establish some intercultural differences among the politeness strategies used in Brazil and in Spain.

Keywords: politeness strategies, social behavior questionnaires, cross-cultural differences Brazil-Spain.

\section{Introdução: as hipóteses de Piatti}

Em estudo que comparava os usos de recursos de atenuação por parte de um grupo de nativos argentinos e outro de estudantes estrangeiros de espanhol, Piatti (2003, p. 206) apontou a existência de diferenças consideráveis entre eles no que diz respeito à necessidade de atenuar os enunciados: enquanto os argentinos suavizam menos uma reclamação quanto maior for o motivo que a geriu, os estrangeiros utilizam mais estratégias de atenuação na realização das reclamações mais sérias. A autora, que fez um levantamento por meio de questionários de hábitos 
sociais dos comportamentos que os participantes adotariam em diversas situações hipotéticas de conflito, coloca vários exemplos que despertaram nosso interesse.

Em casos menores, como quando a conta de um restaurante vem mais alta, os argentinos mostram certa tendência a uma maior atenuação e começam a reclamação com um pedido de desculpa: Disculpáme, me parece que me cobraste de más.

Já nos casos maiores, como quando uma viagem está mal organizada, a reclamação é mais direta, podendo até ser realizada no modo imperativo, com uma prévia preparação (Hacé como quieras, pero devolvéme la plata.), ou por meio de uma asserção impositiva que pode ser acompanhada de uma acusação (Quiero un viaje sin cargo como compensación; Vengo a reclamar mi dinero, no pude hacer las visitas por un problema de ustedes).

Os estrangeiros, no entanto, atenuam mais nos casos de menor seriedade, invertendo a escala de atenuação. No caso do restaurante, fariam uma reclamação mais direta: $\dot{\zeta}$ Estás seguro de que la cuenta es correcta? e, no caso da viagem - ao contrário dos argentinos -, realizariam uma reclamação mais indireta e cortês, dizendo: Discúlpeme, pero el viaje no fue completo, ìme podría dar otro viaje?

Quanto à atenuação dos pedidos, Piatti (2003, p. 208) aponta que os falantes nativos tendem a suavizar mais os pedidos em situações de maior hierarquia, como no caso dos professores, que recorrem a todo tipo de atenuadores para dirigir-se a seus alunos: diminutivos (yo creo que podés dar um poquito más), condicional (mirá, tendrías que revisarlo) e atenuadores semânticos (El trabajo necesita un parde cosas, hay algunos aspectos del tema que no quedaron del todo claros).

Por outro lado, os estrangeiros que participaram do estudo alegaram que nessa mesma situação utilizariam uma estratégia mais direta: El trabajo no está bien, tenés que bacerlo de nuevo; Las ideas no están claras, no entiendo el objetivo del trabajo.

Piatti conclui que as diferenças obtidas entre falantes nativos e estrangeiros -cujas nacionalidades não são especificadas, embora o estudo 
sugira que procedem de diversos lugares - poderiam encontrar uma explicação no fato de que os estrangeiros atenuam mais em situações mais formais de distância social e em situações menos ameaçadoras, enquanto, nos casos de menor distância e de maior ameaça, atentam mais ao conteúdo, a comunicar eficazmente uma mensagem. Já os argentinos buscam a manutenção das relações interpessoais, seja com os amigos, os vizinhos ou inclusive com os alunos.

Mas como seria a situação se esses estrangeiros tivessem um alto domínio da nova língua? Continuaria a prevalecer o conteúdo sobre a forma nas situações de menor distância social e de maior conflito? Ou utilizariam fórmulas e estratégias pragmáticas mais adequadas à situação? Essas foram as interrogantes que inspiraram nosso estudo, que se espelhou, em pequena escala, no modelo de Piatti.

Com um perfil diferente de participantes, esta pesquisa visa ampliar as reflexões sobre a competência pragmática do falante estrangeiro de uma língua, agora focando em falantes com um alto domínio linguístico e cultural que transitam facilmente entre a língua materna e a língua-alvo. Para tanto, foram escolhidas quatro professoras de espanhol, duas espanholas e duas brasileiras, que trabalham nos cursos de Letras da Universidade de Brasília. A escolha das participantes foi motivada pelo fato de todas terem o mesmo nível de proficiência na língua não materna, o que nos possibilitaria fazer o questionário tanto em português quanto em espanhol - para conferir se elas se comportariam de maneira diferente em função do contexto cultural - e também nos ajudaria a identificar diferenças interculturais entre brasileiros e espanhóis.

Segundo Antonio Briz (2002, p. 19), o domínio de uma língua também se manifesta na adequação do uso à situação comunicativa, e um falante apresenta um nível de proficiência alto quando domina os registros correspondentes e é capaz de utilizá-los adequadamente. Se tomarmos essa afirmação como certa, poderemos pressupor que um aprendente de nível superior tem a capacidade de emitir enunciados altamente aceitáveis para os interlocutores da cultura-alvo, provavelmente enunciados de considerável 
elaboração formal. Contudo, sabemos que toda situação comunicativa é imprevisível e que não existem regras infalíveis que nos ensinem a manter um diálogo bem-sucedido com nosso interlocutor, pois o resultado depende em grande medida do contexto, dos sentidos que estão em negociação e da relação entre os interlocutores.

Entretanto, se olharmos para esse evento como um encontro intercultural, devemos levar em conta que não há apenas uma negociação de significados; as formas de interação também devem ser negociadas, dando lugar a novas possibilidades que permitam a manutenção das relações sociais. Nessa negociação, entram em jogo as culturas e as identidades dos interlocutores, com suas ideologias e pontos de vista, o que requer uma flexibilidade e uma capacidade de diálogo especiais. Nesse sentido, concordamos com Byram (1997), segundo o qual essa relação deve ser equitativa, de igual a igual, sem hierarquias que coloquem o estrangeiro em uma posição inferior. Para esse autor, não é uma obrigação do estrangeiro aprender e imitar como um robô as falas e os comportamentos do falante nativo, mas um dever das partes envolvidas identificarem e lidarem com as diferenças culturais que podem chegar a afetar seriamente a comunicação.

$\mathrm{Na}$ mesma linha, Kramsch (1998) considera as ideias de um falante nativo, uma língua e uma cultura nacional uma falácia e afirma que seria mais lógico ver os falantes como pessoas que vão adquirindo, ao longo da vida, um repertório de normas que utilizam cuidadosamente em função dos diversos contextos sociais em que vivem e com os quais chegam a compreender o mundo ao seu redor.

Segundo essas afirmações, as participantes espanholas de nossa pesquisa não precisariam utilizar estratégias diferentes no Brasil com relação à Espanha, mas sim conhecer as expectativas dos brasileiros e saber como manter com eles uma comunicação bem sucedida. Em nosso entendimento, é provável e compreensível que, no seu quotidiano, elas ainda conservem hábitos e peculiaridades de sua cultura sem sofrer atritos com a cultura de acolhida, apesar de já estar residindo no Brasil há mais de cinco anos. Porém, também pressupomos que elas adotam comportamentos mais 
brasileiros em situações em que o nível de ameaça - à sua imagem ou à de seus interlocutores - seja maior; da mesma forma que as participantes brasileiras, que também vivenciaram a experiência de morar em culturas hispânicas, provavelmente recorrem, quando falam espanhol, a estratégias mais adequadas ao contexto com o qual tiveram contato.

\section{Sobre polidez ou cortesia}

Apresentamos a seguir algumas das definições do construto cortesia mais utilizadas no âmbito da Pragmática. Para contextualizar o conceito, discorreremos acerca de noções como imagem social, polidez e atos de fala, definidos por autores da área.

Brown e Levinson (1987, p. 245) partem do pressuposto de que todos os sujeitos têm uma imagem social (face) e, quando se produz o intercâmbio comunicativo com outros sujeitos, essa imagem pode ser ressaltada, mantida ou ameaçada. A imagem positiva se traduz na necessidade dos indivíduos de serem aceitos pela sociedade, e a negativa tem a ver com o desejo particular de cada pessoa de atuar com plena liberdade e manter seu próprio espaço, a despeito da opinião social. Em relação a essa classificação da imagem, diferenciam também a polidez positiva da negativa: a primeira se refere às estratégias, atitudes e comportamentos que visam a mostrar afeto e integrar os indivíduos na situação comunicativa; a negativa se propõe a respeitar e manter o espaço pessoal do indivíduo. De forma geral, os autores entendem a polidez como uma estratégia necessária para manter boas relações sociais e compensar as ameaças à imagem social dos indivíduos, implícitas nos atos comunicativos.

Autores como Kerbrat-Orecchioni (2004) utilizam os termos cortesia valorizadora e cortesia mitigadora para referir-se à positiva e à negativa de Brown e Levinson, que não levam em conta que qualquer uma das duas faces pode ser alvo de ameaças. A polidez mitigadora evita atos que ameacem a imagem do indivíduo, seja esta positiva ou negativa, suaviza os efeitos negativos ou repara a imagem quando o ato é inevitável; enquanto a cortesia valorizadora permite produzir atos corteses com o intuito de 
manter relações sociais harmoniosas e, ao mesmo tempo, reconhecer a imagem do outro. A autora, com quem concordamos, define cortesia como "um conjunto de estratégias de proteção e de valorização das imagens dos outros a fim de preservar 'a ordem da interação"'4 (KERBRAT-ORECCHIONI, 2004, p. 45).

Para Hernández Flores (2002, p. 49), um sentido mais comum do termo alude à atitude considerada socialmente correta que as pessoas mantêm em seus contatos com outros indivíduos. A autora acrescenta que geralmente a cortesia se manifesta em atitudes de respeito e amabilidade perante e com os outros e se associa com a boa educação ou o tratamento agradável, os quais constituem comportamentos sociais considerados positivos pela sociedade. A supracitada pesquisadora afirma que quando esses valores e atitudes dos indivíduos se repetem passam a se tornar regras, normas de comportamento exigidas pela sociedade para manter um equilíbrio das relações sociais, ou seja, um convívio harmonioso. Portanto, a cortesia também pode ser percebida como uma norma social estabelecida que os homens partilham, aceitam e valorizam.

Como aponta Marcuschi (2008, p. 67): "Sempre estamos inseridos num contexto social e em alguma instituição cujos contratos somos obrigados a seguir sob pena de sermos punidos de alguma forma”. De acordo com essa afirmação, os sujeitos ficam atrelados às normas e convenções sociais, embora eles também possuam a liberdade de decidir, influenciados por seus níveis de competência pragmática, sociocultural e linguística, se a situação e os falantes envolvidos exigem e merecem um comportamento cortês, o que os leva a escolher as formas de polidez adequadas para cada situação comunicativa.

As estratégias de polidez podem ser verbais e não verbais, e as verbais, diretas ou indiretas. $\mathrm{Na}$ comunicação, são perceptíveis por meio de elementos lexicais, sintáticos, locuções, fórmulas convencionalizadas, assim como elementos paralinguísticos (a intensidade ou volume da voz, a velocidade de emissão dos enunciados, o tom e as variantes de entonação, o riso, o choro etc.).

4 Do original: "un conjunto de estrategias de protección y de valorización de las imágenes de los demás a fin de preservar "el orden de la interacción". 
Haverkate (1994, apud MONTEIRO, 2008) distingue duas categorias de atos de fala:

- Atos de fala corteses (beneficiam o interlocutor, pressupõem um esforço por parte do falante e geralmente são enunciados de forma direta):

- expressivos: nesta categoria se encontram todos os atos que mostram o estado afetivo ou psicológico do emissor perante uma situação na qual o destinatário forma parte ativa ou passiva (agradecimento, felicitação, pêsame, desculpa, saudação);

- promissivos: atos que expressam a intenção do emissor de realizar ações em benefício do destinatário (promessa, convite).

- Atos de fala não corteses (implicam um custo para o interlocutor e um benefício para o falante. Precisam ser enunciados acompanhados de estratégias de compensação para atenuar a descortesia intrínseca nesses atos):

- assertivos: apoiam a intenção do emissor de tentar convencer o destinatário "de que ele acredita sinceramente que a proposição expressada corresponde a um estado de coisas reais" (repetir palavras, ironizar, afirmar, concluir);

- exortativos:permitem ao emissorinfluenciar no comportamento intencional do destinatário a fim de que ele realize a ação enunciada pelo emissor.

Haverkate (1994) ainda estabelece outra subcategoria para os atos exortativos que, em qualquer caso, se propõem modificar a conduta do destinatário:

- exortativos impositivos: neste caso, o emissor tenta que seu destinatário realize o ato exortado em benefício do próprio emissor (rogo, súplica, mandato); 
- exortativos não impositivos: o emissor tenta conseguir que o destinatário realize o ato exortado em benefício de si próprio (conselho, recomendação, instrução).

\section{A polidez no Brasil e na Espanha: diferenças interculturais}

Segundo Escandell Vidal (1995), os mecanismos de polidez variam de cultura para cultura, sendo as formas utilizadas pelos falantes o aspecto no qual as diferenças podem ser vistas mais claramente, pois estas constituem a vertente mais superficial da polidez. Mas além da forma, tanto as estratégias pragmáticas utilizadas pelos falantes quanto sua valoração social no contexto cultural no qual estão inseridas podem apresentar diferenças interculturais consideráveis.

No que tange ao Brasil e à Espanha, em termos gerais, podemos citar algumas características bastante estendidas no senso comum, ora por causa de estereótipos, ora por narrativas impressionistas de pessoas que comentam os comportamentos lá encontrados. Em nosso entendimento, é bastante generalizada a crença de que os espanhóis não são bons recebendo elogios, assim como a de que os brasileiros não costumam recusar pedidos nem fazer críticas de forma direta, precisando utilizar diversas estratégias de atenuação. Já os espanhóis parecem ter certa tendência à sinceridade sem rodeios, o que chega a causar ofensas graves nos interlocutores estrangeiros.

Já no campo empírico, um estudo desenvolvido por Blum-Kulka e House (1989) para comparar as estratégias mais frequentes em cinco línguas - inglês, alemão, francês, hebraico e espanhol - revelou que o espanhol é a língua que apresenta maior frequência de uso de imperativos e menor frequência de uso de alusões e petições indiretas. $\mathrm{O}$ resultado desse estudo, que talvez possa ser explicado pelo fato de algumas culturas serem mais emotivas e afetivas que outras ${ }^{5}$ (WIERZBICKA, 1991, apud

5 Segundo Wierzbicka (1991), existe a seguinte relação entre os estilos emotivo e de interação: as sociedades nas quais a emoção e a afetividade são associadas ao irracional dão mais importância às estratégias de cortesia negativa; nas sociedades nas quais não é mal visto mostrar abertamente emoção e afeto, dá-se mais importância às estratégias de cortesia positiva. 
ESCANDELL VIDAL, 1995, p. 59), reflete-se na percepção que muitos estrangeiros têm dos espanhóis como "mandões", já que, em outras culturas, o imperativo é menos utilizado.

Outro estudo desenvolvido por Garrido Ardila (2006) aponta que, aos olhos dos britânicos, os espanhóis são demasiado diretos e descorteses, pois realizam os pedidos com os verbos "querer" e "necessitar". Escritores como Elvira Lindo e Javier Marías têm denominado esse fenômeno de economia verbal de "impolidez espanhola"6. Porém, uma cultura não pode ser considerada mais polida que as outras, já que se trata de "tendências divergentes" (SOLER ESPIAUBA, 2010).

Tanto o estudo de Garrido Ardila (2006) quanto o de Haverkate (1994) indicam que a Espanha possui um modelo de polidez voltado para inspirar confiança e obter a benevolência do interlocutor. Segundo os autores, o espanhol tem uma tendência à polidez positiva (familiar ou informal) que contrasta com a polidez negativa (formal) do inglês britânico e de outras línguas europeias.

Mas, se o Brasil também é uma cultura emotiva, quais são suas peculiaridades pragmáticas? De acordo com Garrido Ardila (2006), o português de Portugal se aferra a um estrito modelo de polidez negativa e os imperativos geralmente vão acompanhados de marcadores de polidez ( $f a c ̧ a$ favor, obrigado, com licença ${ }^{7}$ e desculpe). Segundo o autor, as correspondências em português de mandados como ven aqui,dime e no te olvides (espanhol) seriam faça favor de vir cá ou venha cá, faça favor, faça favor de dizer-me e faça favor de não esquecer.

Por outro lado, Meyer e Osório (2008) revelam que, entre o falante português e o falante brasileiro, há diferenças objetivas na realização dos pedidos e nas formas de agradecimento. Em primeiro lugar, os portugueses utilizam formas menos polidas ou mais diretas que os brasileiros, que precisam mais de frases como "por favor". E, ao formular agradecimentos, o brasileiro utiliza formas muito mais prolixas que o português, como nos casos a seguir: (em Portugal) muito obrigado; prazer; tchau; de nada; ou (no

6 Do original: Descortesía española.

7 Do original: Tendencias divergentes. 
Brasil) muito obrigada, meu bem!; o prazer é meu, minha linda!; parece estar numa forma ótima! Sempre é um prazer te ver.

Esses dados parecem indicar que a cultura brasileira é mais negativa que a portuguesa, pois procura resguardar mais a face e manter um trato delicado. Perante a inexistência de estudos comparativos entre o Brasil e a Espanha, partimos dessa hipótese com a expectativa de confirmá-la com a análise dos questionários.

\section{Metodologia}

Este trabalho espelhou-se em uma pesquisa realizada por Piatti (2003) na Argentina com o intuito de comparar as estratégias de polidez que seriam utilizadas em português e em espanhol por quatro professoras universitárias de espanhol, duas espanholas e duas brasileiras, em doze situações hipotéticas apresentadas a elas mediante questionários de hábitos sociais. A metodologia adotada foi a do estudo de caso, pois o escopo foi delimitado a um contexto específico com poucas participantes. A variável que norteou a escolha das participantes foi o nível de proficiência; todas elas deveriam possuir um elevado domínio da segunda língua.

Dessa forma, buscamos explorar as possibilidades de replicação do estudo de Piatti em um contexto diferente daquele observado por ela na Argentina, dessa vez trabalhando com um perfil de participante que poderia apontar diferenças de comportamento que sugerissem o desenvolvimento de sua competência pragmática.

Os dados foram coletados por meio de um teste de hábitos sociais, adaptado do estudo original de Piatti, e sua análise foi desenvolvida mediante a interpretação das respostas obtidas nesses questionários e a subsequente comparação dos resultados com as hipóteses de Piatti.

Os testes ou questionários de hábitos sociais constituem uma técnica de coleta de dados que permite ao pesquisador conhecer os comportamentos sociais de uma sociedade. Conforme lemos em Hernández Flores (2003, p. 186), as perguntas contidas nesses formulários podem ser de dois tipos: demandar dos 
informantes opiniões sobre comportamentos corteses e/ou pedir que escrevam o que diriam em determinadas situações que exigissem estratégias de cortesia. A última técnica foi a escolhida para desenvolver a presente pesquisa.

Os resultados obtidos não são definitivos, mas constituem uma aproximação ao discurso real (PIATTI, 2003, p. 202) dos falantes de uma comunidade e refletem os comportamentos decorrentes das normas e convenções sociais que regem uma sociedade determinada.

As perguntas iniciais que inspiraram o estudo foram: a hipótese de Piatti, segundo a qual os falantes estrangeiros do espanhol atentam mais para o sentido que para a forma, poderia ser estendida aos falantes com um alto domínio da língua? Ou estes utilizariam fórmulas e estratégias pragmáticas mais adequadas ao contexto comunicativo?

Por outro lado, adotamos para o estudo um olhar intercultural que nos levou às seguintes interrogações: quais são as semelhanças e diferenças entre os modelos brasileiro e espanhol de polidez? Seria possível identificálas na análise das respostas de nossas participantes de pesquisa?

As situações apresentadas no questionário foram extraídas do trabalho de Piatti e aludem a situações conflitantes em que as participantes deverão recorrer a estratégias de polidez mitigadora para não ferir ou para preservar a face do outro. A seguir, as perguntas que fizemos às participantes.

\section{Questionário}

Responda o que você diria, em espanhol e em português, nas seguintes situações:

1. Você foi convidada para um jantar. Não gostou da comida, mas comeu. Os anfitriões perguntam se você aceita mais um pouco.

2. Um amigo está usando uma camisa horrível. Ele acabou de comprá-la e quer saber sua opinião.

3. O seu chefe pede para você terminar com urgência um relatório para o dia seguinte. Você tinha se programado para sair com a família depois do trabalho. 
4. Você trabalhou a semana toda e não vê a hora de que chegue a sexta-feira para descansar. Logo depois de deitar, percebe que seu vizinho organizou mais uma de suas festas habituais.

5. Você está numa reunião de amigos. Alguém começa a criticar o partido que governa o país, sabendo que você sempre votou nele.

6. Você contratou uma excursão e perdeu as visitas programadas por causa de problemas com o ônibus da empresa. Você vai na agência reclamar.

7. Você está caminhando por uma rua da cidade e recebe uma cantada de alguém.

8. Você tem que falar para um aluno que o trabalho dele não está bom.

9. O seu chefe está de zíper aberto.

10. Você detesta o cheiro de cigarro na roupa e seus colegas começam a fumar.

11. Um amigo pegou dinheiro emprestado com você e esqueceu-se de devolvê-lo.

12. Sua sogra sugere que você faça remodelações na casa.

A fim de responder nossas perguntas, selecionamos seis categorias de análise que nortearam a comparação das estratégias atenuadoras de polidez utilizadas pelas participantes: uso de diminutivos, expressões indefinidas, perguntas indiretas, justificativas, omissões e fórmulas de assentimento.

\section{Análise dos dados}

Em resposta à primeira pergunta feita no início da pesquisa, a análise dos dados sugeriu que as hipóteses de Piatti não se confirmam no caso de falantes estrangeiras com um alto domínio da língua, pois, em termos gerais, todas as participantes mostraram um cuidado formal e pragmático ao escolher seus enunciados no intuito de adequá-los à situação comunicativa.

Quase todas mostraram variação nas estratégias que usariam nas duas línguas; só uma das participantes brasileiras mostrou uma menor 
variação, pois, em algumas das situações apresentadas, se comportaria da mesma forma em português e em espanhol. Pelo que pudemos observar, nas situações de maior distanciamento social, como nos casos da festa do vizinho, da reclamação na agência de viagens e da resposta à sogra intrometida, essa participante utilizaria menos estratégias de atenuação em espanhol que na sua língua materna, o que não parece ser condizente com a hipótese de Piatti de que os estrangeiros atenuam mais nas situações de maior distância social. Portanto, consideramos que um estudo comparativo entre as estratégias pragmáticas utilizadas por estrangeiros e nativos não pode ser conduzido sem levar em conta quais são as línguas maternas e os níveis de proficiência desses estrangeiros.

Quanto à segunda pergunta, relativa às diferenças interculturais entre Brasil e Espanha, levantamos as seguintes hipóteses a partir das respostas das participantes:

De acordo com as situações 1 e 12, parece que, quando nos oferecem alguma coisa, como comida ou um conselho, é mais fácil recusar a oferta em espanhol que em português. Se a situação é pouco ameaçadora, como no caso da comida, quase todas recusariam a oferta de forma mais atenuada em português, sobretudo as brasileiras, que incluem várias justificativas e estratégias atenuadoras como diminutivos, aumentativos e elogios à comida (“Obrigada, mas já estou super satisfeita. Como como um passarinho”; "Não quero mais não, já estou satisfeita. Estava uma delícia, mas não quero mais"). Também utilizam expressões de agradecimento ("gracias"; "obrigada") para manter uma atmosfera cordial e preparar o ambiente para a posterior resposta, que pode ter efeitos negativos no interlocutor, por causa do desaprecio feito. Já no espanhol, nenhuma ou uma única justificativa seria suficiente. Apenas uma das participantes espanholas sentiria mais necessidade de acrescentar a justificativa de que está satisfeita em espanhol e não em português.

No caso da sogra, quase todas manifestaram que atenuariam bastante mais a resposta em português, especialmente as espanholas, que na sua língua materna sentiriam a liberdade de recusar o conselho, com uma 
prévia expressão de hesitação para preparar a interlocutora ("No sé, a mi me gusta asi”) e até de recusá-lo com um tom de repreensão e um ataque, após um prévio pedido de desculpa pelo que vai falar ("Perdóneme, Silvia, pero yo jamás me he metido en cómo tiene su casa, o le parece que me gusta como la tiene? Pues no, pero jamás le he dicho nada. Pues eso...").

$\mathrm{Na}$ situação 3, predominam as respostas mais diretas em espanhol que em português. Porém, de forma geral, nenhuma falaria ou expressaria diretamente que não gostou da camisa. As participantes espanholas se sentem menos livres para criticar a camisa em português, recorrendo a uma estratégia de atenuação que consiste na formulação de outra pergunta ("Você gostou?"; "Você está mudando de estilo?"). Em geral, todas as respostas vão acompanhadas de uma fórmula de assentimento ("Você não acha?"; "Não?”) para procurar a participação do interlocutor e fazer com que o efeito negativo das implicações seja partilhado. Dessa forma, preserva-se tanto a face de um como a do outro.

Nas situações 3, 5 e 9, as participantes reagiriam de maneira idêntica em português e em espanhol. Acreditamos que elas não sentiram a necessidade de trocar de estratégias ao mudar de língua, porque consideraram as situações igualmente ameaçadoras em ambas as culturas.

A situação 9 representa uma situação indiscreta que pode lacerar a imagem de ambos os falantes, e as participantes possuem domínio das consequências negativas que qualquer enunciado direto poderia trazer nessas circunstâncias, portanto recorrem a várias alternativas: oferecem dicas e sugestões de forma indireta; perguntas retóricas, vagas, que vão sendo acrescentadas no discurso à medida que se desenvolve a situação comunicativa; recorrem ao silêncio para não arcar com a responsabilidade de dizer algo que ameace as faces das pessoas envolvidas; se julgam que existe a confiança necessária, utilizam formas elípticas como "la cremallera"; "o zíper”. O que chama a atenção neste ponto é que uma delas seja capaz de construir um enunciado direto em espanhol ("Llevas la cremallera abierta"), sendo que em português utilizaria uma frase elíptica acompanhada de um elemento extralinguístico (gesto de levantar as sobrancelhas). 
$\mathrm{Na}$ situação 4, uma participante brasileira não diria nada, chamaria diretamente a polícia, e uma das participantes espanholas não diria nada e tentaria dormir (procuraria uma solução antes de fazer alguma coisa que lacerasse a sua imagem social). Mas as outras duas sentiram a necessidade de atenuar muito mais o pedido em português que em espanhol, chegando até a manifestar sua valoração positiva da situação antes de exprimir brevemente o motivo pelo qual precisam de sua cooperação, entendendo que o vizinho está no seu pleno direito de fazer uma festa: "Oi, cara. Sem querer ser chata..."; “Oi, que bom que o senhor tem festa em casa, mas...”.Já em espanhol, essas mesmas participantes foram mais taxativas, embora também tenham utilizado estratégias de atenuação, como as expressões "el menor ruido posible" " "un poco": "Necesito que hagas el menor ruido posible, gracias."; "Mira, es que he tenido que bajar a hablar con vosotros para pediros que bajéis un poco la música. Si no, aqui no hay quién duerma “Oi, que bom que o senhor tem festa em casa, mas...”. Já em espanhol, essas mesmas participantes foram mais taxativas, embora também tenham utilizado estratégias de atenuação, como as expressões el menor ruido posible e un poco: "Necesito que hagas el menor ruido posible, gracias."; "Mira, es que he tenido que bajar a hablar con vosotros para pediros que bajéis un poco la música. Si no, aqui no bay quién duerma".

Pudemos evidenciar, na situação 6, que todas as participantes utilizaram uma linguagem direta para responder às situações em espanhol, chegando as espanholas a serem extremadamente diretas (" $\dot{i}$ Pero se puede saber qué coño le ha pasado al autobús? ¿Voy a perderme el puto viaje porque a usted le da la gana?"; “吕stáis de broma o qué?”), a diferença da linguagem aprimorada e marcadamente polida utilizada em português, com o intuito de diminuir o efeito negativo dos enunciados e procurar a simpatia do interlocutor. Tais sinais de delicadeza são visíveis em: diminutivos ("dinheirinho"), expressões ritualizadas de pedidos de desculpas ("sinto muito") e perguntas enunciadas em futuro do pretérito, tendentes a marcar a distância social e formular os pedidos de forma mais cortês ("gostaria de saber").

$\mathrm{Na}$ situação 7, uma das participantes brasileiras não aceitaria uma cantada na rua em nenhuma das duas línguas, e uma espanhola a aceitaria nas duas. Já 
as outras duas mostraram uma pequena variação que parece apontar que, no Brasil, esse tipo de ato tem mais aceitação social que na Espanha: enquanto elas aceitariam a cantada no Brasil ("Obrigada"; "Dou um sorrisinho e continuo caminhando"), na Espanha fingiriam não ter ouvido.

A situação 8 reflete uma relação hierárquica professor-aluno. Piatti, em seu estudo, afirma que os professores argentinos tendem a usar formas corteses no seu relacionamento com os alunos no ambiente de sala de aula. No entanto, o que se pode inferir das respostas obtidas no presente questionário é que quase todas as participantes mantêm um trato mais respeitoso e alentador com seus alunos na língua portuguesa, usando mais estratégias de atenuação ("Gostei do trabalho, mas tem algumas coisinhas que precisa melhorar"; "Sinto muito, mas você não demonstrou o quanto pode neste trabalho"; "Está horrível. Você não fez nada do que pedi”) que na língua espanhola, na qual expressam mais abertamente sua inconformidade com o trabalho ("La verdad es que no te hases forzado mucho. Tú podrias hacerlo muchisimo mejor. Esperaba mucho más de ti, no me defraudes, ¿̨vale?"; "No has hecho lo que te he pedido"; "Está un poco inadecuado. No tiene mucho que ver con lo que les pedi").

A situação 10 mostra uma peculiaridade da cultura do cigarro na Espanha, onde é comum frequentar lugares nos quais a maioria fuma e as pessoas não se sentem à vontade para reclamar ou pedir que os outros parem de fumar. Enquanto as participantes brasileiras agiriam do mesmo modo nas duas línguas (recorrendo a uma pergunta para sugerir que estão incomodadas e uma justificativa para explicar por quê: “¿No les molesta que me vaya? Porque el tabaco me deja con mucha alergia"; "Vocês não se importam se eu não ficar com vocês, não é? É que tenho uma alergia terrível à fumaça"), uma das participantes espanholas não diria nada (ela gosta do cheiro) e a outra realizaria um pedido mais indireto em espanhol (“'№ os molesta ese olor?") que em português ("Você devia parar de fumar").

As evidências encontradas na situação 11 apontam que na Espanha é menos problemático pedir o dinheiro de volta. Quase todas as participantes utilizaram mais estratégias de atenuação em português, incluindo justificativas que lhes permitiriam inverter a situação e pedir dinheiro ao interlocutor de maneira espontânea, evitando, assim, ferir a 
face do interlocutor com a acusação de que não pagou o que devia: "Ih! Esqueci o dinheiro, tem cinco reais aí?”. Uma das participantes espanholas chegou inclusive a manifestar que, se o valor fosse pequeno, ela não pediria o dinheiro de volta no Brasil (apesar de que em espanhol faria o pedido de maneira direta, seguido de uma explicação: "Bueno, ¿̇y cuándo piensas devolverme lo que te presté? Es que me va a hacer falta para arreglar el coche").

\section{Considerações finais}

Apesar das evidentes limitações deste estudo, no qual apenas pudemos trabalhar com quatro participantes, consideramos que os resultados revelaram informações consistentes sobre o desenvolvimento da competência pragmática dos falantes de uma língua estrangeira, que, pelo menos no caso observado, se constituem como falantes plurilíngues e pluriculturais que conhecem e sabem comportar-se em função das regras sociais decorrentes dos diversos contextos comunicativos.

Entretanto, as escolhas das participantes parecem reforçar nossa hipótese de que a Espanha tem um modelo mais positivo de polidez que o Brasil, pois existe mais liberdade para realizar pedidos e reclamações em situações de conflito, sem necessidade de recorrer a estratégias de cortesia. Os elogios, ao contrário, parecem ter uma maior aceitação social no Brasil, onde exaltar a imagem do outro é um recurso importante para manter o equilíbrio das relações sociais.

Esses dados vão ao encontro das hipóteses que inspiraram nosso estudo, refutando - ou melhor, ampliando - as hipóteses formuladas por Piatti sobre o aprendente estrangeiro que fala a língua-alvo. Como pudemos constatar, os falantes com um alto domínio da língua e da cultura-alvo conseguem elaborar enunciados formalmente elaborados e pragmaticamente adequados em muitas das situações hipotéticas apresentadas sem necessidade de imitar os costumes e atitudes do nativo.

Os resultados obtidos nos questionários, de natureza empírica, não pretendem ser gerais nem possuir valor de verdade universal, se levarmos 
em consideração que as respostas oferecidas pelas informantes não necessariamente serão partilhadas por outros membros da sociedade, mas constituem uma fonte valiosa de informação acerca de atitudes, crenças, valores, convenções e comportamentos sociais característicos das culturas brasileira e espanhola, foco do nosso estudo. Além do mais, nos concedeu a oportunidade de extrair algumas diferenças interculturais entre as estratégias de polidez utilizadas nas duas culturas.

\section{Referências}

BARROS GARCÍA, María Jesús. La cortesía: un saber fundamental en la enseñanza de lenguas. Boletín de la Asociación para la enseñanza del español como lengua extranjera, n. 42, mayo, p. 13-19, 2010.

BLUM-KULKA, Shohana; HOUSE, Juliane. Cross-cultural and situational variation in requestive behavior in five languages. In: BLUMKULKA, Shohana; HOUSE, Juliane; KASPER, Gabriele (Eds.). Crosscultural pragmatics. Norwood, NJ: Ablex, 1989. p. 123-154.

BRIZ, Antonio. El español coloquial en la clase de E/LE: un recorrido a través de los textos. Madrid: SGEL, 2002.

BROWN, Penelope; LEVISON, Stephen C. Politeness: some universals in language use. Cambridge: Cambridge University Press, 1987.

BYRAM, Michael. Teaching and assessing intercultural communicative competence. Clevedon: Multilingual Matters, 1997.

ESCANDELL VIDAL, Maria Victoria. Introducción a la pragmática. Barcelona: Ariel, 2006.

. Cortesía, fórmulas convencionales y estrategias indirectas. Revista Española de Lingüistica, n. 25, v. 1, p. 31-66, 1995.

GARRIDO ARDILA, Juan Antonio. Confianza y norma social en la cortesía lingüística. Estudios de Lingüistica de la Universidad de Alicante, n. 20, p. 13-31, 2006. 
HAVERKATE, Henk. La cortesía verbal: estudio pragmalingüístico. Madrid: Gredos, 1994.

HERNÁNDEZ FLORES, Nieves. Los tests de hábitos sociales y su uso en el estudio de la cortesía: una introducción. In: PRIMER COLOQUIO DEL PROGRAMA EDICE, 2003, Estocolmo. Actas... Estocolmo, 2003, p. 186-197.

- La cortesía en la conversación española de familiares y amigos: la búsqueda de equilibrio entre la imagen del hablante y la imagen del destinatario. 2002. Tese (Doutorado em Línguas e Estudos Culturais Internacionais) Aalborg Universitet, Aalborg, 2002.

KERBRAT-ORECCHIONI, Catherine. ¿Es universal la cortesía? In: BRAVO, Diana; BRIZ, Antonio (Eds.). Pragmática sociocultural: estudios sobre el discurso de cortesía en español. Barcelona: Ariel, 2004. p. 39-54.

KRAMSCH, Claire. Language and culture. Oxford: Oxford University Press, 1998.

MARCUSCHI, Luiz Antônio. Produção textual, análise de gêneros $e$ compreensão. 2. ed. São Paulo: Parábola, 2008.

MEYER, Rosa Marina B.; OSÓRIO,Paulo. Contribuições para uma didática das "formas de agradecimento" em PL2E: um estudo de caso. In: REBELO, Ida Maria M.; JÚDICE, Norimar; ALMEIDA, Patrícia C. Português para estrangeiros: territórios e fronteiras. Rio de Janeiro: PUC-Rio, 2008.

MONTEIRO, Flávia A. Agradecimentos e desculpas em português brasileiro e em espanhol: um estudo comparado de polidez a partir de roteiros cinematográficos contemporâneos. Dissertação (Mestrado em Letras Neolatinas) - Universidade Federal do Rio de Janeiro, Rio de Janeiro, 2008.

PIATTI, Guillermina. La elaboración de tests de hábitos sociales para la enseñanza del español como lengua extranjera. In: PRIMER COLOQUIO DEL PROGRAMA EDICE.EDICE, 2003, Estocolmo. Actas... Estocolmo, 2003.p. 203-211. 
SOLER ESPIAUBA, Dolores. Compartir el ADN cultural en el aula de E/2L. In: PRIMER CONGRESO INTERNACIONAL EN LA RED SOBRE INTERCULTURALIDAD EDUCACIÓN, 2010. Disponível em: <http://letra25.com/ediciones/cii-martes2/soler/files/soler.pdf>. Acesso em: 10 jun. 2010.

WIERZBICKA, Ana. Cross-cultural Pragmatics: the semantics of human interaction. Berlin: Mouton-De Groyter, 1991. 